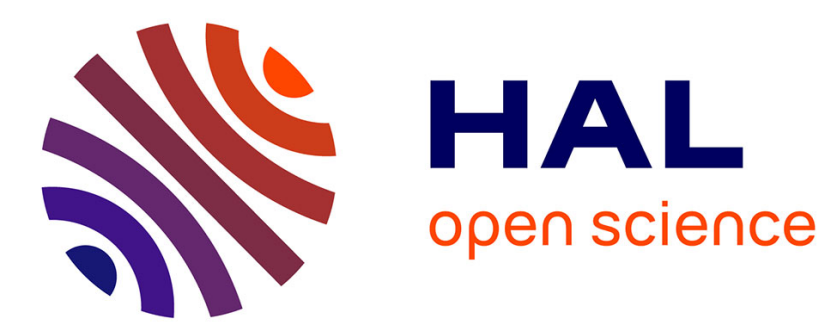

\title{
The Composition of Compensation Policy: From Cash to Fringe Benefits
}

Patricia Crifo, Marc-Arthur Diaye

\section{To cite this version:}

Patricia Crifo, Marc-Arthur Diaye. The Composition of Compensation Policy: From Cash to Fringe Benefits. 2005. hal-00243030

\section{HAL Id: hal-00243030 \\ https://hal.science/hal-00243030}

Preprint submitted on 6 Feb 2008

HAL is a multi-disciplinary open access archive for the deposit and dissemination of scientific research documents, whether they are published or not. The documents may come from teaching and research institutions in France or abroad, or from public or private research centers.
L'archive ouverte pluridisciplinaire HAL, est destinée au dépôt et à la diffusion de documents scientifiques de niveau recherche, publiés ou non, émanant des établissements d'enseignement et de recherche français ou étrangers, des laboratoires publics ou privés. 


\title{
ECOLE POLYTECHNIQUE
}

CENTRE NATIONAL DE LA RECHERCHE SCIENTIFIQUE

\section{The Composition of Compensation Policy: From Cash to Fringe Benefits}

\author{
Patricia Crifo \\ Marc-Arthur Diaye
}

Novembre 2005

Cahier $n^{\circ}$ 2005-041

\section{LABORATOIRE D'ECONOMETRIE}

1rue Descartes F-75005 Paris

(33) 155558215

http://ceco.polytechnique.fr/

mailto:labecox@poly.polytechnique.fr 


\title{
The Composition of Compensation Policy: From Cash to Fringe Benefits
}

\author{
Patricia Crifo ${ }^{1}$ \\ Marc-Arthur Diaye ${ }^{2}$
}

Novembre 2005

Cahier $n^{\circ} \quad$ 2005-041

Résumé: $\quad$ Cet article développe un modèle principal-agent pour analyser la composition optimale des politiques de rémunérations en présence d'incitations monétaires et non monétaires. On caractérise les bénéfices non monétaires comme des symboles pour capturer un ensemble large de compensations non monétaires telles que les avantages en natures, le statut, l'identité ou même les sanctions. Nous montrons que lorsque les préférence des agents sont de connaissance commune les incitations non monétaires sont toujours plus efficaces que les incitations monétaires. Nous caractérisons également la composition optimale du schéma de rémunération lorsque le principal ne connaît qu'imparfaitement les préférences des agents. En particulier, nous montrons que des avantages en nature fixes combinés à un salaire variable sont plus rentables pour le principal dans ce contexte.

Abstract: In this paper, we develop a Principal-Agent model to analyze the optimal composition of the compensation policy with both monetary and nonmonetary incentives. We characterize nonmonetary benefits as symbols to capture a large set of non-wage compensations such as fringe benefits, status, identity (or self-image) or even sanctions. We show that when the agent's preference relation over monetary and nonmonetary benefits is common knowledge to both parties, nonmonetary incentives are always more efficient, that is Pareto-dominate, monetary incentives. We also characterize the optimal composition of the compensation policy when the principal imperfectly knows the agent's preferences. In particular, we show that a fixed fringe benefits coupled with a variable wage improves profits under this imperfect knowledge structure.

Mots clés : $\quad$ Relation d'agence, Incitations non monétaires

Key Words : Fringe benefits, Agency Relationships, Non-Monetary Incentives

Classification JEL: J30, J32, J33

\footnotetext{
${ }^{1}$ Laboratoire d’Econométrie, CNRS et Ecole polytechnique.

${ }^{2}$ Centre d'Etudes de l'Emploi et Université d'Evry.
} 


\title{
THE COMPOSITION OF COMPENSATION POLICY: FROM CASH TO FRINGE BENEFITS
}

\author{
PATRICIA CRIFO AND MARC-ARTHUR DIAYE
}

\section{INTRODUCTION}

This paper contributes to the debate on firm's optimal compensation policy by focusing on the composition of the pay package in terms of monetary and nonmonetary (fringe) benefits. A firm's compensation policy can be broken into three independent dimensions: the level, the functional form and the composition (Baker et al.[4]). The level of compensation determines the quality and quantity of employees - that is who the firm can attract, the functional form determines the links between pay and performance - that is how employees perform once they're hired, and the composition defines the relative amounts of the components of the pay package such as cash, fringe benefits, working conditions, relationships with coworkers, leisure etc. Most of the existing work on incentives have privileged the first two dimensions.

It is conventional wisdom in the management and organization literature that "knowing when to use travel, merchandize or cash to reward employees increases the odds of a successful incentive "(Wood [25]). The optimal composition of the compensation policy hence is a crucial issue in the design of incentives by employers. However, this issue has been surprisingly left aside of economic analysis until recent years. Empirical evidence on this topics is also relatively scarce and mostly concentrated in the literature on fringe benefits. Fringe benefits vary from one country to another, but typically include pension scheme, health and life insurance, stock options, free car, free housing or lower valued fringes like free coffee for instance, and fringe benefit policies represent a significant component of firms' compensation policy. Overall non-wage labor costs would account for 15 to 40 percent of total labour costs in major OECD countries (Dale-Olsen [6]). Recent studies also aim at providing empirical estimate of employees preference for non-wage benefits like health insurance (Royalty [23] and Goldman et al. [13]) or on the consequences of fringe benefits on labor market indicators such as employment, worker turnover or firm's survival and productivity (Dale-Olsen [6] and [5], Hashimoto et al. [16]).

A related literature has investigated the role of perquisites (perks) in executive compensation, where perks refer to "forms of nonmonetary compensation offered to select employees ... not strictly necessary for the accomplishment of the employee's

Date: February 2006.

Key words and phrases. Fringe benefits, Agency Relationships, Non-Monetary Incentives, Perquisites. JEL Codes: J30, J32, J33.

We wish to thank for their comments Emrah Arbak and the participants at EPEE (University of Evry), ERMES (University of Paris 2) and CECO (Ecole Polytechnique, PREG). 
duties"(Rajan and Wulf [22]). In the corporate finance literature, perks are often considered as a way for managers to misappropriate some of the firm's surplus. Excessive perks may indeed reflect wasteful corporate practices such as overinvestment and lax management. More generally, as any type of private benefits they would exemplify agency costs and inefficiencies: "they are attractive to management but of no interest to shareholders - in fact they reduce firm value" (Hart [14]). However, there is no consensus on this explanation of perks as private benefits and there are alternative theories of why firms might offer perks. They might indeed be awarded to enhance managerial productivity and/or let the CEO signal his status and reinforce his standing in the organization.

The idea that nonmonetary variables play an important role in firms' compensation and employment policy is not new and goes back to Adam Smith (1776). In Rosen [24]'s theory of compensating differentials, the nonpecuniary components of a job are transformed into their monetary equivalent to quantify the value of a job. However, only recent years have witnessed an increasing interest in the study of the determinants and labor market consequences of non-wage compensations. This renewed interest stems from arguments and criticisms raised in management and/or social psychology leading to treat fringe benefits as non-wage job amenities. Despite their monetary value, fringe benefits would not be equivalent to money wages for psychological reasons like endowments effects (employees might be more attached to fringe benefits than the equivalence in money) or framing effects (leading employees to evaluate fringe benefits differently than cash) (Kahneman et al. $[18])$.

In turn, a growing literature has developed the past decade to study work motivation, in particular building on the distinction between intrinsic and extrinsic motivation and incentives. Departing from the assumption of purely self-interested agents, this literature has explored the psychological effects of monetary rewards on motivation and effort (see Frey [11] and Kreps [19]). The motivation crowding effect theory relies on the idea that there is a psychological process which underlies intrinsic motivation and extrinsic incentives. Monetary rewards may thus reduce intrinsic motivation: where individuals perceive an external intervention to be controlling, their intrinsic motivation to perform the task diminish (see Deci and Ryan $[8])$.

However, as pointed out by Akerlof and Kranton [1], "A source of motivation is missing from current models of organizations. [We] characterize this missing source as identity. By identity, we mean a person's self image - as an individual and as part of a group. (...) In the Army as well as in civilian organizations, such identification - or lack of it - plays a critical role in determination of work effort, incentive schemes, and organizational design." By incorporating the psychology of identity into economic analysis of work incentives, Akerlof and Kranton [1] hence build another bridge between social psychology and economics within recent developments of agency theory.

Such approaches provide an excellent analysis of psychological motives and their effect on work motivation and effort within agency relationships. Our ambition is different: without departing from the assumption of purely self-interested agents, our goal is to determine the optimal composition of the compensation policy of a firm in terms of monetary and nonmonetary benefits. We will not explore the 
psychological channels through which nonmonetary benefits affect individual motivation, but rather focus on the design of the compensation policy mix as an incentive device when that agents value both monetary and nonmonetary benefits. As a consequence, we will also characterize the links between both kinds of rewarding tools in terms of relative complementarity or substitutability.

We consider a moral hazard model in which the transfer between the principal and the agent is non-purely monetary in the sense that it is composed of a monetary wage (which may be fixed or null) and a nonmonetary reward that depends on the state of nature (i.e. the occurrence of specific events observable by both parties). Our definition of non-purely monetary incentives hence is rather large: we consider a general utility function with two arguments, monetary and nonmonetary, explicitly dependent on the state of nature and thereby allowing for many different notions of nonpecuniary rewards like a medal, a promotion without a wage increase, a prize etc.

In an analogous perspective, Auriol and Renault [2] propose a moral hazard model in which agents receive both wage and non-wage compensations. They introduce directly a status variable in the utility function to reflect an agent's claim to social recognition in work. While we also consider preferences defined directly over monetary and nonmonetary arguments, our model is quite different because we are able to captures more nonmonetary compensation tools than simply social status. The first novelty of our approach thus lies in the degree of generality of the compensation mix offered by the principal which may range from cash to fringe benefits, hierarchical status, identity (or self-image) or even sanctions (the nonmonetary part is not restricted to be positive).

Moreover, we use a general utility function such that preferences are not required a priory to exhibit income-status complementarity. In fact, we analyze the degree of congruence between monetary and nonmonetary benefits in the optimal compensation policy mix proposed by the principal under different functional forms. The second novelty of our approach hence consists in deriving the optimal composition of the compensation policy mix, and illustrating the trade-off between wage and non-wage benefits in terms of relative complementarity or substitutability.

Finally, our results also depend on whether the principal knows the agent's "value system". Intuitively this means the value of a job to the employee, according to a set of criteria comprising wage and fringe benefits, social status, symbols. More generally, this notion of value system could also be associated with the notion of adhesion to a norm, defined by sociologists as a "general rule of voluntary behavior" (see for instance the discussion by Kreps [19]). Indeed, a particular social norm can be considered as a particular value system to which the agent adheres. Whether the employer knows the agent's value system is a crucial question to design good management practice. When selecting the mix of reward options proposed to their employees, the employers' final judgment should not resemble a guess more than a well-informed choice. To avoid this, regular surveys and other forms of communication diffuse within firms. For instance, Wood [25] documents three types of fringe benefits: travel, merchandize or cash programs and indicates that unlike cash, merchandizes have a high trophy value but are not as exciting as travels. On a more general level, the trade-off between monetary and nonmonetary benefits depends on the employer's information about the agent's value system because purely 
financial incentive schemes can induce significant adverse side effects, and mainly two: motivation and equity concerns. According to the former -motivational- effect, money would lower employee motivation by reducing the intrinsic rewards of a job(see Frey et al. [12]). According to the latter -equity concerns- adverse effect of financial incentives, horizontal inequity among workers would reduce morale and productivity. Knowing the agent's system value hence is crucial to determine the optimal wage and non-wage compensation policy. Our results are first derived in the case of full knowledge by the principal, but interestingly they remain valid under a weaker knowledge structure.

To discuss the optimal composition of the compensation package and the tradeoff between monetary and nonmonetary benefits, our article is composed of five sections. Section 2 describes preferences and profit functions. Section 3 and 4 derive the main results of our model. Finally, section 6 concludes the article.

\section{The Model}

\subsection{Nonmonetary rewards as symbols.}

We consider a Principal-Agent relationship with moral hazard ${ }^{1}$ in which the Principal designs the optimal contract by proposing monetary and/or nonmonetary incentives. We label nonmonetary incentives under the term of symbol. The notion of symbol allows capturing the fact that nonmonetary benefits may range from fringe benefits (e.g. pension scheme, health and life insurance, stock options, free car) to nonmonetary incentives which have a trophy value (like travel) or affect a person's image, either her self-image (i.e. identity as this is the case in Akerlof and Kranton [1]), or her social image (for instance status in the organization as in Auriol and Renault [2]).

To give examples of various symbols, we can think of receiving a medal (military or civil like an olympic medal), a promotion (without a significant wage increase), an academic prize (e.g. Nobel Prize ${ }^{2}$, Social Choice and Welfare Prize ${ }^{3}$, Gold Medal of the French CNRS, etc.), a business award (e.g. being elected the "Manager of the year") or recognition (like a business car, a business flat, a travel, flowers, a big office etc.) or belonging to a selective club (like Rotary Club), a national sport team (soccer, rugby etc.), or a professional society (e.g. Econometric Society).

Let $\Omega$ be the infinite overall set of all symbols. These symbols that serve as non-monetary incentives may be divisible as well as indivisible but they are not immediately liquid for the Agent who receives them. Their role therefore does not consist in yielding a monetary revenue to the Agent. We have to define costs and preferences associated with such symbols.

Offering symbols to the agent is not costless for the principal. Let $c$ denote the cost function for the principal, $c: \Omega \longrightarrow \mathbb{R}_{+}$where $c(\omega)$ is the production cost by the Principal for the symbol $\omega$.

\footnotetext{
${ }^{1}$ The analysis can be extended to any other type of agency relationship (adverse selection, signalling,...).

${ }^{2}$ Most researchers would prefer to obtain the Nobel prize even without the monetary reward associated rather than the pure monetary reward, without the title "Nobel".

${ }^{3}$ No monetary reward is associated to this prize.
} 
Given a standard preference relation $\succsim$ defined over the set of symbols $\Omega$, let $s=h(\omega)$ denote the symbolic equivalent of $\omega \in \Omega$ in $\mathbb{R}$. $h$ represents the nonmonetary reward associated with symbol $\omega$ and may be interpreted as a selfsatisfaction or "ego"function (the agent prefers $\omega$ to $\omega^{\prime}$ because $\omega$ provides more self-esteem than does $\left.\omega^{\prime}\right)$. Basically, rather than the set of symbols $\Omega$, we will therefore use $S$, a set of real numbers equivalent to these symbols.

Given function $h$, the cost function defined over the set $S$ is denoted by $\widetilde{c}$, where:

$$
\begin{aligned}
\widetilde{c}: S & \longrightarrow \mathbb{R}_{+} \\
s & \longmapsto \widetilde{c}(s)=c\left(h^{-1}(s)\right)
\end{aligned}
$$

To simplify notations, and when no confusion arises, we will replace the notation $\widetilde{c}$ by $c$. Note that function $c$ is not necessarily either monotonically increasing or decreasing but $c$ is assumed to be twice continuously differentiable.

Finally, the output of the relationship between the principal and the agent is a random (observable) variable and we denote by $X$ the set of outputs. The agent's reward is composed of a a (standard) monetary wage $w: X \longrightarrow W$, and a nonmonetary component $s: X \longrightarrow S$ where $W$ is the set of monetary wages, $W \subseteq \mathbb{R}_{+}^{*}$.

\subsection{Technology and preferences.}

Given the costs and rewards defined previously, we characterize in this section the principal's profit, the agent's utility and effort and the output of the relationship.

The risk-neutral Principal profit function is defined by:

$$
B(x-w-c(s))=x-w-c(s)
$$

where $w$ denotes the agent's monetary reward, $c(s)$ is the $\mathrm{C}^{2}$ cost of the nonmonetary reward and $x \in X$ is the observable random output.

The Agent is risk-averse, with a utility function defined by:

$$
\tilde{U}(w, s, e)=\tilde{u}(w, s)-v(e)
$$

where $e$ is the agent's effort, $e \in \mathbb{R}_{+} ; \tilde{u}$ is a strictly increasing concave utility function, and $v(e)$ is the agent's cost of effort: $v^{\prime}(e)>0, v^{\prime \prime}(e) \geq 0, v(0)=0$

We further assume that the agent's effort level can take two possible values: $e \in\left\{e^{L}, e^{H}\right\}$ with $e^{L}<e^{H}$, the stochastic production level $x$ can take take $n$ possible values: $x \in X=\left\{x_{1}, \ldots, x_{n}\right\}$ where $x_{1}<x_{2}<x_{3}<\ldots<x_{n}$; and the stochastic influence of effort in production is defined by the probabilities $p_{i}^{H}=$ $\operatorname{Pr}\left(x=x_{i} \mid e=e^{H}\right)>0, p_{i}^{L}=\operatorname{Pr}\left(x=x_{i} \mid e=e^{L}\right)>0$.

Assumption 1. The probabilities of success satisfy the monotone likelihood ratio property: $\frac{p_{i}^{H}-p_{i}^{L}}{p_{i}^{H}}$ is nondecreasing in $i$. 
Two particular cases are worth highlighting. The first one corresponds to the standard Principal-Agent framework, where the agent's utility depends on monetary rewards only: $U(w, e)=u(w)-v(e)$, with $u^{\prime}(w)>0, u^{\prime \prime}(w) \leq 0, u(0)=0$. In this situation, the Principal solves the following program:

$(\mathrm{PMON})$

$$
\begin{aligned}
& \underset{\left\{w\left(x_{i}\right)\right\}_{i=1}^{n}}{\operatorname{Max}} \sum_{i=1}^{n} p_{i}^{H}\left(x_{i}-w\left(x_{i}\right)\right) \\
& \text { s.t. } \\
& \sum_{i=1}^{n} p_{i}^{H} u\left(w\left(x_{i}\right)\right)-v\left(e^{H}\right) \geq \underline{U} \\
& \sum_{i=1}^{n}\left(p_{i}^{H}-p_{i}^{L}\right) u\left(w\left(x_{i}\right)\right) \geq v\left(e^{H}\right)-v\left(e^{L}\right)
\end{aligned}
$$

where the first constraint is the participation constraint, the second one is the incentive compatibility constraint, and $\underline{U}$ is the Agent's reservation utility.

The second situation corresponds to a pure nonmonetary incentives scheme where the agent's utility would depend on nonmonetary rewards only: $G(s, e)=$ $g(s)-v(e)$, with $g^{\prime}(s)>0, g^{\prime \prime}(s) \leq 0$. The main difference between $u$ and $g$ is that $g(s)$ can be negative in the case where $s$ is a negative incentive (sanction). When there is no monetary wage, the Principal solves the following program :

(PNMO1)

$$
\mid \begin{aligned}
& \underset{\left\{s\left(x_{i}\right)\right\}_{i=1}^{n}}{\operatorname{Max}} \sum_{i=1}^{n} p_{i}^{H}\left[x_{i}-c\left(s\left(x_{i}\right)\right)\right] \\
& \text { s.t. } \\
& \sum_{i=1}^{n} p_{i}^{H} g\left(s\left(x_{i}\right)\right)-v\left(e^{H}\right) \geq \underline{U} \\
& \sum_{i=1}^{n}\left(p_{i}^{H}-p_{i}^{L}\right) g\left(s\left(x_{i}\right)\right) \geq v\left(e^{H}\right)-v\left(e^{L}\right)
\end{aligned}
$$

In this situation the program (PNMO1) does not necessarily admit a solution (see appendix). In particular, if the cost function is strictly decreasing then the program (PNMO1) has no solution. Decreasing symbolic costs are not outliers per se and we give an example that illustrates it in the following subsection. The absence of solution in such a case stems from the fact that there is a contradiction between the profit maximizing objective of the Principal and the participation and incentive constraints. This property is interesting because it shows that using symbols as incentive devices in agency problems is not trivial even when the costs of providing symbols are decreasing. To avoid this problem, we therefore assume for the rest of the paper that:

Assumption 2. $c$ the cost function is a strictly increasing convex function.

\subsection{The agent's value system.}

Given that the incentives scheme is composed of a monetary wage and a nonmonetary reward, knowing the agent's value system is crucial to determine the optimal composition of the compensation package. Wood [25] documents that "The best salespeople like to wow others with their sales number. And when it comes to their reward, they have to be wowed... travel does this better than any other incentive." In other words, the more informed the decision, the better the odds of a successful incentive policy. The knowledge structure for the principal is defined as follows.

Definition 1. The agent's value system is represented by the agent's preference relation $\succsim$, captured through function $h$. Full knowledge by the principal refers to the case where $h$ is common knowledge to both parties. 
The value that the Agent attributes to a symbol depends on the way this Agent internalizes and interprets this symbol, that is on her value system (a notion that could be linked to social or personal norms). The full information (common knowledge) case serves as the benchmark situation, but alternative knowledge structures will also be analyzed. When the agent's system value is not common knowledge, the agent's preference relation is a private information, it is conditional to his observation of a random variable $\theta \in \Theta$. We denote by $\succsim^{\theta}$ this preference relation, and by $h(\omega, \theta)$ the corresponding real-valued function - symbolic equivalent. Three subcases can then be distinguished:

Case 1. The Principal does not know (and has no prior on) the probability distribution of $\theta$. In this case, the principal can only resort to pure monetary incentives.

Case 2. The Principal knows the probability distribution of $\theta$. In this case, a mixed monetary/nonmonetary incentives mechanism can be designed by working on the expected self-satisfaction of a symbol $\omega$ denoted $\widehat{h}(\omega)=\widehat{s}=E_{\Theta}[h(\omega, \theta)]$.

Case 3. The Principal does not know (and has no prior on) the probability distribution of $\theta$ but she knows that there exist (at least) two symbols $\omega^{\prime}, \omega^{\prime \prime} \in \Omega$ such that $\omega^{\prime} \succ \omega^{\prime \prime}$. This is the case we will analyze more specifically in section 5 .

\section{OPTIMAL COMPENSATION UNDER COMPLETE INFORMATION}

In this section we characterize the optimal compensation scheme when the agent's value system is common knowledge to both parties. In modern firms or organizations, the agent cannot be paid only with symbols and a monetary reward is included in the contract. Let us therefore consider a mixed incentives scheme composed of a monetary and a nonmonetary reward, in which the Principal solves the following program :

(PMIX)

$$
\mid \begin{aligned}
& \underset{\left\{w\left(x_{i}\right), s\left(x_{i}\right)\right\}_{i=1}^{n}}{\operatorname{Max}} \sum_{i=1}^{n} p_{i}^{H}\left[x_{i}-w\left(x_{i}\right)-c\left(s\left(x_{i}\right)\right)\right] \\
& \text { s.t. } \\
& \sum_{i=1}^{n} p_{i}^{H} \tilde{u}\left(w\left(x_{i}\right), s\left(x_{i}\right)\right)-v\left(e^{H}\right) \geq \underline{U} \\
& \sum_{i=1}^{n}\left(p_{i}^{H}-p_{i}^{L}\right) \tilde{u}\left(w\left(x_{i}\right), s\left(x_{i}\right)\right) \geq v\left(e^{H}\right)-v\left(e^{L}\right)
\end{aligned}
$$

The optimal compensation policy that solves program (PMIX) is characterized by the following proposition.

Proposition 1. If the agent's value system is common knowledge, then the optimal solution of (PMIX), $\left\{w^{*}\left(x_{i}\right), s^{*}\left(x_{i}\right)\right\}_{i=1}^{n}$, is such that

$$
\frac{\widetilde{u}_{s}^{\prime}\left(w^{*}\left(x_{i}\right), s^{*}\left(x_{i}\right)\right)}{\widetilde{u}_{w}^{\prime}\left(w^{*}\left(x_{i}\right), s^{*}\left(x_{i}\right)\right)}=c^{\prime}\left(s^{*}\left(x_{i}\right)\right), \quad \forall x_{i} \in X .
$$

and therefore exhibits stronger wage/symbol substitutability for low wage levels, and higher wage/symbol congruence at high wage levels. 
The fact that the optimal compensation policy depends on the degree of substitutability between monetary and nonmonetary rewards relies on the fact that $\frac{\widetilde{u}_{s}^{\prime}(., .)}{\widetilde{u}_{w}^{\prime}(., .)}$ measures the marginal rate of substitution between symbol and wage. This property is based on the concavity of the utility function. Basically, in the plane $\left(w\left(x_{i}\right), s\left(x_{i}\right)\right)$, a convex indifference curve exhibits diminishing marginal rate of substitution between $w\left(x_{i}\right)$ and $s\left(x_{i}\right), \frac{\widetilde{u}_{w}^{\prime}(., .)}{\widetilde{u}_{s}^{\prime}(., .)}$, and increasing marginal rate of substitution between $s\left(x_{i}\right)$ and $w\left(x_{i}\right), \frac{\widetilde{u}_{s}^{\prime}(., .)}{\widetilde{u}_{w}^{\prime}(., .)}$. Put differently, when the agent has a higher monetary wage, she is willing to give up more monetary wage in exchange of obtaining equal amounts of nonmonetary symbols. In other words, substitutability between wage and symbol is lower for lower wage levels.

This property holds for standard utility functions and it is interesting to consider the case where $\widetilde{u}$ is a CES fonction: $\tilde{u}\left(w\left(x_{i}\right), s\left(x_{i}\right)\right)=\left[w\left(x_{i}\right)^{-\varepsilon}+s\left(x_{i}\right)^{-\varepsilon}\right]^{-\frac{v}{\varepsilon}}$ with $\varepsilon \geq-1$. Then the optimality condition derived from proposition 1 writes: $\left(\frac{w^{*}\left(x_{i}\right)}{s^{*}\left(x_{i}\right)}\right)^{\varepsilon+1}=c^{\prime}\left(s^{*}\left(x_{i}\right)\right)$, that is: $\frac{w^{*}\left(x_{i}\right)}{s^{*}\left(x_{i}\right)}=\left[c^{\prime}\left(s^{*}\left(x_{i}\right)\right)\right]^{\frac{1}{\varepsilon+1}}$. We see that $\frac{w^{*}\left(x_{i}\right)}{s^{*}\left(x_{i}\right)}$ is a decreasing function of $\varepsilon$, where the elasticity of substitution between $w\left(x_{i}\right)$ and $s\left(x_{i}\right)$ is $\sigma=\frac{1}{1+\varepsilon}$. As $\varepsilon$ increases, $s$ and $w$ become less and less substitutable. In the limit case $\varepsilon=+\infty, s$ and $w$ are complementary, and given the optimality condition $\frac{w^{*}\left(x_{i}\right)}{s^{*}\left(x_{i}\right)}=\left[c^{\prime}\left(s^{*}\left(x_{i}\right)\right)\right]^{\frac{1}{\varepsilon+1}}$ then $w^{*}\left(x_{i}\right)=s^{*}\left(x_{i}\right)$. When $\varepsilon$ decreases, $s$ and $w$ become more substitutable and $w / s$ increases.

In other words, the degree of substitutability between both rewards shapes the use of cash or fringe benefits as relative complements or substitutes in the optimal composition of the compensation package. There is some empirical evidence in line with this issue. Dale-Olsen [5] shows that for non-public sector establishments offering fringe benefits in Norway in 2002, there seems to exist a positive correlation between wages and fringe benefits. However, when accounting for the size of the establishments then Norwegian manufacturing is actually characterized by a convex relationship between fringe benefits and workforce size to the position in the conditional wage distribution. This convex relationship means that high wage establishments offer more fringes to their employees and have a higher size, but very low wage establishments also offer more fringes and are large. These facts are not inconsistent with our assessment that substitutability is lower for lower wage levels.

Let us now consider the following program:

(PMIX2)

$$
\mid \begin{aligned}
& \underset{\left\{s\left(x_{i}\right)\right\}_{i=1}^{n}}{\operatorname{Max}} \sum_{i=1}^{n} p_{i}^{H}\left[x_{i}-c\left(s\left(x_{i}\right)\right)\right]-\bar{w} \\
& \text { s.t. } \\
& \sum_{i=1}^{n} p_{i}^{H} \tilde{u}\left(\bar{w}, s\left(x_{i}\right)\right)-v\left(e^{H}\right) \geq \underline{U} \\
& \sum_{i=1}^{n}\left(p_{i}^{H}-p_{i}^{L}\right) \tilde{u}\left(\bar{w}, s\left(x_{i}\right)\right) \geq v\left(e^{H}\right)-v\left(e^{L}\right)
\end{aligned}
$$

where $\bar{w} \geq I_{\Lambda}, I_{\Lambda}$ being the certainty equivalent of lottery

$$
\Lambda=\left(p_{1}^{H}, w^{*}\left(x_{1}\right) ; \ldots ; p_{n}^{H}, w^{*}\left(x_{n}\right)\right)
$$

Comparing programs (PMIX2) and (PMON) yields the following proposition. 
Proposition 2. If the principal knows the agent's value system, the optimal mechanism which solves program (PMIX2), $\left\{\bar{w}, s^{*}\left(x_{i}\right)\right\}_{i=1}^{n}$, where $s^{*}\left(x_{i}\right)$ is defined by:

$$
\frac{\tilde{u}_{s}^{\prime}\left(\bar{w}, s^{*}\left(x_{i}\right)\right)}{c^{\prime}\left(s^{*}\left(x_{i}\right)\right)}=\frac{1}{\lambda_{3}+\mu_{3}\left(1-\frac{p_{i}^{L}}{p_{i}^{H}}\right)}
$$

with $\lambda_{3}, \mu_{3}$, the strictly positive Lagrange multipliers of (PMIX2), is such that the agent:

- faces a lower risk exposure in terms of monetary wage, compared to the case of pure monetary incentives mechanism

- is indifferent between the contract with mixed compensations (PMIX2) and the contract with purely monetary incentives (PMON).

Proposition 2 states that the Principal can use nonmonetary incentives in order to reduce the agent's risk exposure in terms of monetary reward because the agent is indifferent between the pure monetary contract (PMON) and a mixed contract (PMIX2), where the monetary reward is equal or higher than the certainty equivalent of the pure monetary "lottery" $\Lambda=\left(p_{1}^{H}, w^{*}\left(x_{1}\right) ; \ldots ; p_{n}^{H}, w^{*}\left(x_{n}\right)\right)$ where:

$$
w^{*}\left(x_{i}\right)=u^{\prime-1}\left(\frac{1}{\lambda+\mu\left(1-\frac{p_{i}^{L}}{p_{i}^{H}}\right)}\right)
$$

with $\lambda$ and $\mu$ are strictly positive Lagrange multipliers.

We are now going to examine the optimal composition of the compensation policy, that is the relative importance between the symbolic and the monetary reward, when the agent's system value is common knowledge. Section 5 will then relax this assumption and characterize the optimal contract under imperfect knowledge regarding the agent's system value.

\section{Optimal Composition of the COMPEnsation POliCy: the trade-OFF BETWEEN MONETARY AND MIXED INCENTIVES}

At first glance, one might think that when the Principal has more instruments when she uses a mixed monetary/nonmonetary incentives mechanism, then the latter will automatically increases her profit. Nevertheless, this statement is not true. Indeed, if the principal can use more incentives instruments in the mixed monetary/nonmonetary incentives mechanism, she also faces more costs. If, for instance $c\left(s\left(x_{i}\right)\right)=w\left(x_{i}\right)$ whatever $x_{i} \in X$, then a mixed monetary/non-monetary incentives mechanism will reduce the principal's profit compared to the purely monetary incentives mechanism. Therefore the issue of the optimal composition of the compensation policy is not trivial.

Let $\Pi_{M O N}^{*}$ the Principal's optimal profit in the program (PMON) and $\Pi_{M I X}^{*}$ the Principal's optimal profit in the program (PMIX). We will show that if the Principal knows the Agent's value system, then under the weak condition set in assumption 3 we have $\Pi_{M O N}^{*}<\Pi_{M I X}^{*}$. 
Let $\phi(x \mid e)$ be the conditional distribution and $\varphi(x \mid e)$ be the everywhere positive density function.

Assumption 3. Let $\{s(x)\}$ be a sequence of non-monetary incentives, then :

$$
E(s)=\int_{X} s(x) \varphi(x \mid \bar{e}) d x>E(c(s))=\int_{X} c(s(x)) \varphi(x \mid \bar{e}) d x
$$

where $\bar{e}$ which is the effort's level required by the Principal.

Let us note that if the Principal knows the Agent's preferences then assumption 3 is not too much constraining because the set of non-monetary incentives is sufficiently large. The trade-off between monetary and mixed incentives packages is characterized as follows.

Theorem 1. When the Principal knows the Agent's value system then : if there exists an optimal pure monetary incentives scheme $\left\{w^{*}\left(x_{i}\right)\right\}_{i=1}^{n}$ which solves the program (PMON), then there exists an optimal mixed monetary / nonmonetary incentives scheme $\left\{w_{m i x}^{*}\left(x_{i}\right), s^{*}\left(x_{i}\right)\right\}_{i=1}^{n}$ solution of the program (PMIX) which guarantees to the Principal an expected profit strictly higher:

$$
\Pi_{M I X}^{*}>\Pi_{M O N}^{*}
$$

and which guarantees the same expected utility to the Agent:

$$
\sum_{i=1}^{n} p_{i}^{H} \tilde{u}\left(w_{m i x}^{*}\left(x_{i}\right), s^{*}\left(x_{i}\right)\right)-v\left(e^{H}\right)=\sum_{i=1}^{n} p_{i}^{H} u\left(w^{*}\left(x_{i}\right)\right)-v\left(e^{H}\right)
$$

This result indicates that if the Principal knows the Agent's preferences over the set of symbols $\Omega$ then all what a pure monetary incentives scheme can provide, a mixed monetary/non-monetary incentives scheme can provide it as well: a mixed monetary/non-monetary incentives scheme Pareto-dominates a purely monetary incentives scheme.

Corollary 1. When the Principal knows the Agent's value system then: if there exists an optimal pure monetary incentives scheme $\left\{w^{*}\left(x_{i}\right)\right\}_{i=1}^{n}$ which solves the program (PMON) then there exists a (non optimal) mixed monetary/ nonmonetary incentives scheme $\left\{w_{\text {mix }}\left(x_{i}\right), s\left(x_{i}\right)\right\}_{i=1}^{n}$ which provides an expected profit to the Principal $\Pi_{M I X}$ such that:

$$
\Pi_{M I X}^{*}>\Pi_{M I X} \geq \Pi_{M O N}^{*}
$$

and which guarantees to the Agent a higher expected utility:

$$
\sum_{i=1}^{n} p_{i}^{H} \tilde{u}\left(w_{m i x}\left(x_{i}\right), s\left(x_{i}\right)\right)-v\left(e^{H}\right)>\sum_{i=1}^{n} p_{i}^{H} u\left(w^{*}\left(x_{i}\right)\right)-v\left(e^{H}\right)
$$

This Corollary states that if the Principal is ready to accept a profit $\Pi_{M I X}$ strictly lower than $\Pi_{M I X}^{*}$ (but still greater than $\Pi_{M O N}^{*}$ ), then there exists a mixed monetary/non-monetary incentives scheme which Pareto-dominates strictly the solution given by a pure monetary incentives scheme. 
THE COMPOSITION OF COMPENSATION POLICY: FROM CASH TO FRINGE BENEFITSI

We are now going to examine the case where the agent's value system is not common knowledge.

\section{The AGent's VAlue SYSTEM IS NOT COMMON KNOWLEDGE}

When the agent's system value is not common knowledge, then the agent's preference is conditional to his observation of a random variable $\theta \in \Theta: \succsim^{\theta}$. Three situations may arise then:

- when the principal does not know (and has no prior on) the probability distribution of $\theta$, only a standard purely monetary incentives mechanism can be proposed to the agent.

- when the principal knows the probability distribution of $\theta$, a mixed monetary/nonmonetary incentives mechanism can be designed using the expected self-satisfaction of a symbol $\omega, \widehat{h}(\omega)=\widehat{s}=E_{\Theta}[h(\omega, \theta)]$.

However it seems reasonable to consider that in most empirical problems, we are only in the following third case.

- the principal does not know (and has no prior on) the probability distribution of $\theta$, but knows that there exist (at least) two symbols $\omega^{\prime}, \omega^{\prime \prime} \in \Omega$ such that $\omega^{\prime} \succ \omega^{\prime \prime}$.

In this intermediate case, the principal knows that there exists a symbol $\omega^{\prime}$ which is not strictly dominated by any other symbol. Hence, the Principal can use this symbol when designing the optimal composition of the incentives scheme. In turn, let us now consider the following program:

(PMIX3)

$$
\mid \begin{aligned}
& \underset{\left\{w\left(x_{i}\right)\right\}_{i=1}^{n}}{\operatorname{Max}} \sum_{i=1}^{n} p_{i}^{H}\left[x_{i}-w\left(x_{i}\right)\right]-s^{\prime} \\
& \text { s.t. } \\
& \sum_{i=1}^{n} p_{i}^{H} \tilde{u}\left(w\left(x_{i}\right), s^{\prime}\right)-v\left(e^{H}\right) \geq \underline{U} \\
& \sum_{i=1}^{n}\left(p_{i}^{H}-p_{i}^{L}\right) \tilde{u}\left(w\left(x_{i}\right), s^{\prime}\right) \geq v\left(e^{H}\right)-v\left(e^{L}\right)
\end{aligned}
$$

where $s^{\prime}$ is the non-monetary reward associated with symbol $\omega^{\prime}$.

Since the principal uses only one symbol, then assumption 3 writes: $s^{\prime}>c\left(s^{\prime}\right)$. The optimal compensation package is then characterized by the following proposition.

Proposition 3. When the Principal does not know (and has no prior) the probability distribution of $\theta$ but knows that there exist (at least) two symbols $\omega^{\prime}, \omega^{\prime \prime} \in \Omega$ such that $\omega^{\prime} \succ \omega^{\prime \prime}$, then the optimal incentive mechanism derived from program (PMIX3) $\left\{w^{*}\left(x_{i}\right), s^{\prime}\right\}_{i=1}^{n}$ where $s^{\prime}$ is the non-monetary reward associated with symbol $\omega^{\prime}$, and $w^{*}\left(x_{i}\right)$ the monetary component is defined by:

$$
\tilde{u}_{w}^{\prime}\left(w^{*}\left(x_{i}\right), s^{\prime}\right)=\frac{1}{\lambda_{4}+\mu_{4}\left(1-\frac{p_{i}^{L}}{p_{i}^{H}}\right)}
$$

with $\lambda_{4}, \mu_{4}$, the strictly positive Lagrange multipliers. This compensation package, solution of program (PMIX3), always Pareto-dominates purely monetary incentives, solution of program (PMON). 
This proposition shows that even when the principal imperfectly knows the agent's value system, a mixed (non purely) monetary incentives scheme still exists. The agent is ex ante indifferent between a monetary and a non-pure monetary incentives mechanisms because in both case she obtains exactly the same reservation utility. Moreover, a mixed (monetary/nonmonetary) incentives mechanism increases the principal's profit. This proposition is important for empirical purpose since in most firms and organizations, many fringe benefits are not conditioned to the firm's result. This is the case for instance of health insurance, nursery, or free car. The proposition leads to the following prediction : using a fixed fringe benefit and a variable salary as an incentive device actually improves the Principal's profit. Actually, it seem that one should distinguish among nonmonetary incentives between fixed fringe benefits offered by the principal for instance to retain employees and reduce turnover (see Dale-Olsen [5]), and symbols with a high trophy value (for instance like status in the organization) for which the principal could have more knowledge in terms of the agent's system value and could be profitably linked to the firm's results.

\section{Conclusion}

This article shows that a mixed monetary/non-monetary incentives scheme may be more efficient than a standard monetary scheme and that an imperfect knowledge of the agent's preferences influences the optimal composition of the compensation policy in favor of fixed fringe benefits and variable wages.

From an economic policy perspective, taking into account the tax system ${ }^{4}$ might reinforce our results in the following sense. A mixed monetary/non-monetary incentives scheme would be more interesting both for the principal and for the agent under a progressive tax system for the lower part of the income distribution subject to a traditional threshold level. Indeed, for such categories of workers, a monetary bonus may sometimes be completely suboptimal when it implies that the agent switches up to the higher income category, making her pay taxes and losing social transfers. For the principal as well, if labor taxes are progressive, a non-purely monetary incentives scheme represents a non-negligible fiscal advantage, even though we have seen that the role of cost in the optimal compensation package is not trivial.

While this paper does not provide per se a novel formalization of intrinsic versus extrinsic motivations, our results can shed a new light on this debate. Frey et al. [12] define intrinsic motivation as "activities one simply undertakes because one likes to do them or because the individual derives some satisfaction from doing his or her duty". Purely monetary incentives induce hidden costs for the principal, as shown formally within agency contexts by Lane [20], and Benabou and Tirole [3] among others. Since we show that mixed monetary/non-monetary incentives are more profitable than purely monetary ones, our approach supports the idea that nonmonetary compensations also offset the "hidden costs of rewards".

\footnotetext{
${ }^{4} \mathrm{~A}$ formal analysis of the incidence of non-monetary incentives within a macroeconomic framework with a third party - the government - and a specific tax policy is outside the scope of this paper.
} 
Among the main factors that contribute to raise intrinsic motivation, incentives schemes which are not perceived by the agent as designed to monitor her behavior but rather designed to reward ex post the effort level (thereby being discretionary) and more generally, incentives schemes which send a positive signal to the agent regarding her "self-determination "positively affect intrinsic motivation. In turn, our model can be interpreted as one in which a mixed monetary/non-monetary incentives scheme increases intrinsic motivation on the basis of these factors. Indeed, let us consider the mixed compensation policy $\left\{w^{*}, s\left(x_{i}\right)\right\}_{i=1}^{n}$ where $w^{*}$ is fixed. This incentives scheme will not be perceived by the agent as designed to monitor her behavior because the monetary component $w^{*}$ is the same whatever the result $x_{i}$. The non-monetary symbol associated $\omega\left(x_{i}\right)$ varies with the results but it is not a monetary wage. The agent will perceive it as an ex post reward for the effort provided. If for instance $X=\left\{x_{1}, x_{2}\right\}$ with $\omega\left(x_{1}\right)=$ "scooter" , $\omega\left(x_{2}\right)=$ "car" , $w^{0}=3000 U S D /$ month and if $x=x_{2}$ occurs; the agent will consider the car given by the Principal as a discretionary reward aimed at rewarding her effort. It is both a prize (since it rewards an effort) and a gift from the Principal (since it shows that her work is publicly recognized). And this is the case all the more as, according to our results, the principal can build the monetary system in such a way that the agent obtains an expected utility strictly higher than under a monetary incentive scheme. Besides, since a symbol is perceived by the agent as a discretionary reward, then the agent will behave more in favor of the organization. Indeed, according to Fehr and Gachter [10], and Akerlof and Kranton [1], a gift (from the principal) induces reciprocity (from the agent), and hence increases the agent's intrinsic motivation.

Finally, let remind that the agent's utility is given by : $\tilde{U}(w, s, e)=\tilde{u}(w, s)-v(e)$ where $s=h(\omega)$ is the non-monetary wage obtained by the agent from symbol $\omega$ and can be interpreted as an index of "ego" or self-satisfaction, whereby nonmonetary rewards offset the motivation crowding-out effect of price incentives. 


\section{APPENDIX: PROOFS}

Proof: (PNMO1) does not necessarily admit a solution. We can solve the program (PNMO1) using Kuhn and Tucker method because on the one part the cost function is twice continuously differentiable and on the other part $\sum_{i=1}^{n} p_{i}^{H} g\left(s\left(x_{i}\right)\right)$ and $\sum_{i=1}^{n}\left(p_{i}^{H}-p_{i}^{L}\right) g\left(s\left(x_{i}\right)\right)$ are concave functions. However the solution if it exists is a local maximum. Let $L\left(s\left(x_{1}\right), \ldots, s\left(x_{n}\right), \lambda_{1}, \mu_{1}\right)$ the Lagrangean of program (PNMO1) with $\lambda_{1}, \mu_{1} \geq 0$. Kuhn and Tucker's conditions are given as follows:

(a) $-p_{i}^{H} c^{\prime}\left(s\left(x_{i}\right)\right)+\lambda_{1} p_{i}^{H} g^{\prime}\left(s\left(x_{i}\right)\right)+\mu_{1}\left(p_{i}^{H}-p_{i}^{L}\right) g^{\prime}\left(s\left(x_{i}\right)\right)=0$

(b) $\lambda_{1}\left[\sum_{i=1}^{n} p_{i}^{H} g\left(s\left(x_{i}\right)\right)-v\left(e^{H}\right)-\underline{U}\right]=0$

(c) $\mu_{1}\left[\sum_{i=1}^{n}\left(p_{i}^{H}-p_{i}^{L}\right) g\left(s\left(x_{i}\right)\right)-v\left(e^{H}\right)+v\left(e^{L}\right)\right]=0$

Equation $(a)$ also writes :

$$
\lambda_{1} p_{i}^{H}+\mu_{1}\left(p_{i}^{H}-p_{i}^{L}\right)=p_{i}^{H} \cdot \frac{c^{\prime}\left(s\left(x_{i}\right)\right)}{g^{\prime}\left(s\left(x_{i}\right)\right)}
$$

Hence we have:

$$
\lambda_{1}=\sum_{i} p_{i}^{H} \cdot \frac{c^{\prime}\left(s\left(x_{i}\right)\right)}{g^{\prime}\left(s\left(x_{i}\right)\right)}
$$

Recall however that while $g^{\prime}\left(s\left(x_{i}\right)\right)>0$, we have made no assumption about the monotony of cost function $c$. If this function is strictly decreasing then $\sum_{i} p_{i}^{H} \cdot \frac{c^{\prime}\left(s\left(x_{i}\right)\right)}{g^{\prime}\left(s\left(x_{i}\right)\right)}<$ 0 and we have a contradiction with. $\lambda_{1} \geq 0$. Therefore if the cost function is strictly decreasing then program (PNMO1) admits no solution. We have the same conclusion if $c$ is not monotone decreasing but is such that $\sum_{i} p_{i}^{H} \cdot \frac{c^{\prime}\left(s\left(x_{i}\right)\right)}{g^{\prime}\left(s\left(x_{i}\right)\right)}<0$.

Proof of proposition 1. We can solve the program (PMIX) using Kuhn and Tucker method because on the one part the cost function is a convex function and on the other part $\sum_{i=1}^{n} p_{i}^{H} \tilde{u}\left(w\left(x_{i}\right), s\left(x_{i}\right)\right)$ and $\sum_{i=1}^{n}\left(p_{i}^{H}-p_{i}^{L}\right) \tilde{u}\left(w\left(x_{i}\right), s\left(x_{i}\right)\right)$ are negative semidefinite functions. Moreover the solution if it exists is a global maximum. Let $L\left(w\left(x_{1}\right), \ldots, w\left(x_{n}\right) ; s\left(x_{1}\right), \ldots, s\left(x_{n}\right), \lambda_{2}, \mu_{2}\right)$ the Lagrangean of program (PMIX) with $\lambda_{2}, \mu_{2} \geq 0$. Kuhn and Tucker's conditions are given as follows:

(a) $-p_{i}^{H}+\lambda_{2} p_{i}^{H} \tilde{u}_{w}^{\prime}\left(w\left(x_{i}\right), s\left(x_{i}\right)\right)+\mu_{2}\left(p_{i}^{H}-p_{i}^{L}\right) \tilde{u}_{w}^{\prime}\left(w\left(x_{i}\right), s\left(x_{i}\right)\right)=0$

(b) $-p_{i}^{H} c^{\prime}\left(s\left(x_{i}\right)\right)+\lambda_{2} p_{i}^{H} \tilde{u}_{s}^{\prime}\left(w\left(x_{i}\right), s\left(x_{i}\right)\right)+\mu_{2}\left(p_{i}^{H}-p_{i}^{L}\right) \tilde{u}_{s}^{\prime}\left(w\left(x_{i}\right), s\left(x_{i}\right)\right)=0$

(c) $\lambda_{2}\left[\sum_{i=1}^{n} p_{i}^{H} \tilde{u}\left(w\left(x_{i}\right), s\left(x_{i}\right)\right)-v\left(e^{H}\right)-\underline{U}\right]=0$

(d) $\mu_{2}\left[\sum_{i=1}^{n}\left(p_{i}^{H}-p_{i}^{L}\right) \tilde{u}\left(w\left(x_{i}\right), s\left(x_{i}\right)\right)-v\left(e^{H}\right)+v\left(e^{L}\right)\right]=0$

(a) writes also:

$$
\lambda_{2} p_{i}^{H}+\mu_{2}\left(p_{i}^{H}-p_{i}^{L}\right)=\frac{p_{i}^{H}}{\tilde{u}_{w}^{\prime}\left(w\left(x_{i}\right), s\left(x_{i}\right)\right)}
$$

Hence :

$$
\lambda_{2}=\sum_{i} \frac{p_{i}^{H}}{\tilde{u}_{w}^{\prime}\left(w\left(x_{i}\right), s\left(x_{i}\right)\right)}
$$


Since $\tilde{u}_{w}^{\prime}\left(w\left(x_{i}\right), s\left(x_{i}\right)\right)>0$ then $\lambda_{2}>0$ (we reach exactly the same conclusion using Kuhn and Tucker condition (b)). Concerning $\mu_{2}$, if $\mu_{2}=0$ then $(a)$ and $(b)$ implies respectively that:

$$
\lambda_{2}=\frac{1}{\tilde{u}_{w}^{\prime}\left(w\left(x_{i}\right), s\left(x_{i}\right)\right)}
$$

and

$$
\lambda_{2}=\frac{c^{\prime}\left(s\left(x_{i}\right)\right)}{\tilde{u}_{s}^{\prime}\left(w\left(x_{i}\right), s\left(x_{i}\right)\right)}
$$

$\lambda_{2}=\frac{1}{\tilde{u}_{w}^{\prime}\left(w\left(x_{i}\right), s\left(x_{i}\right)\right)}$ implies that (using implicit functions theorem) $w\left(x_{i}\right)=\phi\left(\lambda_{2}, s\left(x_{i}\right)\right)$. Therefore, $\lambda_{2}=\frac{c^{\prime}\left(s\left(x_{i}\right)\right)}{\tilde{u}_{s}^{\prime}\left(w\left(x_{i}\right), s\left(x_{i}\right)\right)}$ also writes:

$$
\lambda_{2}=\frac{c^{\prime}\left(s\left(x_{i}\right)\right)}{\tilde{u}_{s}^{\prime}\left[\phi\left(\lambda_{2}, s\left(x_{i}\right)\right), s\left(x_{i}\right)\right]}
$$

Let us denote $\frac{c^{\prime}\left(s\left(x_{i}\right)\right)}{\tilde{u}_{s}^{\prime}\left[\phi\left(\lambda_{2}, s\left(x_{i}\right)\right), s\left(x_{i}\right)\right]}$ by $\psi\left(s\left(x_{i}\right)\right)$ then the previous equation becomes :

$$
\lambda_{2}=\psi\left(s\left(x_{i}\right)\right)
$$

That is :

$$
s\left(x_{i}\right)=\psi^{-1}\left(\lambda_{2}\right)
$$

In other words, the Agent receives the same symbol whatever the result. In this case, the Agent will choose the lowest effort level $e^{L}$. Therefore, such a mechanism is not optimal. Hence we have $\mu_{2}>0$. The optimal mixed monetary/non-monetary incentives scheme is given by :

$$
\begin{aligned}
& \left\{w^{*}\left(x_{i}\right), s^{*}\left(x_{i}\right)\right\}_{i=1}^{n} \\
& \text { such that } \\
& \frac{\widetilde{u}_{s}^{\prime}\left(w^{*}\left(x_{i}\right), s^{*}\left(x_{i}\right)\right)}{\widetilde{u}_{w}^{\prime}\left(w^{*}\left(x_{i}\right), s^{*}\left(x_{i}\right)\right)}=c^{\prime}\left(s^{*}\left(x_{i}\right)\right), \quad \forall x_{i} \in X .
\end{aligned}
$$

Proof of proposition 2. We can solve the program (PMIX2) using Kuhn and Tucker method because on the one part the cost function is a convex function and on the other part $\sum_{i=1}^{n} p_{i}^{H} \tilde{u}\left(\bar{w}, s\left(x_{i}\right)\right)$ and $\sum_{i=1}^{n}\left(p_{i}^{H}-p_{i}^{L}\right) \tilde{u}\left(\bar{w}, s\left(x_{i}\right)\right)$ are concave in $s$. Hence the solution if it exists is a global maximum. Let $L\left(\bar{w} ; s\left(x_{1}\right), \ldots, s\left(x_{n}\right), \lambda_{3}, \mu_{3}\right)$ the Lagrangean of program (PMIX2) with $\lambda_{3}, \mu_{3} \geq 0$. Kuhn and Tucker's conditions are given as follows:

$$
\begin{aligned}
& \text { (a) }-p_{i}^{H} c^{\prime}\left(s\left(x_{i}\right)\right)+\lambda_{3} p_{i}^{H} \tilde{u}_{s}^{\prime}\left(\bar{w}, s\left(x_{i}\right)\right)+\mu_{3}\left(p_{i}^{H}-p_{i}^{L}\right) \tilde{u}_{s}^{\prime}\left(\bar{w}, s\left(x_{i}\right)\right)=0 \\
& \text { (b) } \lambda_{3}\left[\sum_{i=1}^{n} p_{i}^{H} \tilde{u}\left(\bar{w}, s\left(x_{i}\right)\right)-v\left(e^{H}\right)-\underline{U}\right]=0 \\
& \text { (c) } \mu_{3}\left[\sum_{i=1}^{n}\left(p_{i}^{H}-p_{i}^{L}\right) \tilde{u}\left(\bar{w}, s\left(x_{i}\right)\right)-v\left(e^{H}\right)+v\left(e^{L}\right)\right]=0
\end{aligned}
$$

(a) writes also:

$$
\lambda_{3} p_{i}^{H}+\mu_{3}\left(p_{i}^{H}-p_{i}^{L}\right)=p_{i}^{H} \cdot \frac{c^{\prime}\left(s\left(x_{i}\right)\right)}{\tilde{u}_{s}^{\prime}\left(\bar{w}, s\left(x_{i}\right)\right)}
$$

Hence :

$$
\lambda_{3}=\sum_{i} p_{i}^{H} \cdot \frac{c^{\prime}\left(s\left(x_{i}\right)\right)}{\tilde{u}_{s}^{\prime}\left(\bar{w}, s\left(x_{i}\right)\right)}
$$


Since $\tilde{u}_{s}^{\prime}\left(\bar{w}, s\left(x_{i}\right)\right)$ and $c^{\prime}\left(s\left(x_{i}\right)\right)$ are strictly positive then $\lambda_{3}>0$. Concerning $\mu_{3}$, if $\mu_{3}=0$ then $(a)$ implies that:

$$
\lambda_{3}=\frac{c^{\prime}\left(s\left(x_{i}\right)\right)}{\tilde{u}_{s}^{\prime}\left(\bar{w}, s\left(x_{i}\right)\right)}=\psi\left(s\left(x_{i}\right)\right)
$$

That is :

$$
s\left(x_{i}\right)=\psi^{-1}\left(\lambda_{3}\right)
$$

In other words, the Agent receives the same symbol whatever the result. In this case, the Agent will choose the lowest effort level $e^{L}$. Therefore, such a mechanism is not optimal. Hence we have $\mu_{3}>0$. The optimal incentives scheme is given by :

$$
\begin{aligned}
& \left\{\bar{w}, s^{*}\left(x_{i}\right)\right\}_{i=1}^{n} \\
& \text { such that } \\
& \frac{\widetilde{u}_{s}^{\prime}\left(\bar{w}, s^{*}\left(x_{i}\right)\right)}{c^{\prime}\left(s^{*}\left(x_{i}\right)\right)}=\frac{1}{\lambda_{3}+\mu_{3}\left(1-\frac{p_{i}^{L}}{p_{i}^{H}}\right)}, \quad \forall x_{i} \in X .
\end{aligned}
$$

The Agent is indifferent between the solution of (PMIX2) and the one of (PMON) because in both case he gets his reservation utility. However his risk exposure concerning his monetary wage is reduced since he is risk-averse in $w$ and he gets $\bar{w} \geq I_{\Lambda}$ the certainty equivalent of $\Lambda=\left(p_{1}^{H}, w^{*}\left(x_{1}\right) ; \ldots ; p_{n}^{H}, w^{*}\left(x_{n}\right)\right)$, the lottery faced by the Agent in the pure monetary incentives mechanism.

Proof of proposition 3. We can solve the program (PMIX3) using Kuhn and Tucker method because on the one part the cost function is a convex function and on the other part $\sum_{i=1}^{n} p_{i}^{H} \tilde{u}\left(w\left(x_{i}\right), s^{\prime}\right)$ and $\sum_{i=1}^{n}\left(p_{i}^{H}-p_{i}^{L}\right) \tilde{u}\left(w\left(x_{i}\right), s^{\prime}\right)$ are concave in $w$. Hence the solution if it exists is a global maximum. Let $L\left(w\left(x_{1}\right), \ldots, w\left(x_{n}\right) ; s^{\prime} ; \lambda_{4}, \mu_{4}\right)$ the Lagrangean of program (PMIX3) with $\lambda_{4}, \mu_{4} \geq 0$. Kuhn and Tucker's conditions are given as follows:

$$
\begin{aligned}
& \text { (a) }-p_{i}^{H}+\lambda_{4} p_{i}^{H} \tilde{u}_{w}^{\prime}\left(w\left(x_{i}\right), s^{\prime}\right)+\mu_{4}\left(p_{i}^{H}-p_{i}^{L}\right) \tilde{u}_{w}^{\prime}\left(w\left(x_{i}\right), s^{\prime}\right)=0 \\
& \text { (b) } \lambda_{4}\left[\sum_{i=1}^{n} p_{i}^{H} \tilde{u}\left(w\left(x_{i}\right), s^{\prime}\right)-v\left(e^{H}\right)-\underline{U}\right]=0 \\
& \text { (c) } \mu_{4}\left[\sum_{i=1}^{n}\left(p_{i}^{H}-p_{i}^{L}\right) \tilde{u}\left(w\left(x_{i}\right), s^{\prime}\right)-v\left(e^{H}\right)+v\left(e^{L}\right)\right]=0
\end{aligned}
$$

(a) writes also:

$$
\lambda_{4} p_{i}^{H}+\mu_{4}\left(p_{i}^{H}-p_{i}^{L}\right)=\frac{p_{i}^{H}}{\tilde{u}_{w}^{\prime}\left(w\left(x_{i}\right), s^{\prime}\right)}
$$

Hence :

$$
\lambda_{4}=\sum_{i} \frac{p_{i}^{H}}{\tilde{u}_{w}^{\prime}\left(w\left(x_{i}\right), s^{\prime}\right)}
$$

Since $\tilde{u}_{w}^{\prime}\left(w\left(x_{i}\right), s^{\prime}\right)$ is strictly positive then $\lambda_{4}>0$. Applying the same reasoning as in the previous proof we have $\mu_{4}>0$. The optimal incentives scheme is given by:

$$
\begin{aligned}
& \left\{w^{*}\left(x_{i}\right), s^{\prime}\right\}_{i=1}^{n} \\
& \text { such that } \\
& \tilde{u}_{w}^{\prime}\left(w^{*}\left(x_{i}\right), s^{\prime}\right)=\frac{1}{\lambda_{4}+\mu_{4}\left(1-\frac{p_{i}^{L}}{p_{i}^{H}}\right)}, \quad \forall x_{i} \in X .
\end{aligned}
$$


THE COMPOSITION OF COMPENSATION POLICY: FROM CASH TO FRINGE BENEFITSI7

Lemma 1. Let denote by $q$ : the following random variable

$$
q=w^{*}(x)-c\left(s^{*}(x)\right)-w_{m i x}^{*}(x)
$$

$q$ denotes the difference between the optimal wage of the monetary incentives scheme $w^{*}(x)$ and the overall cost of the mixed monetary/non-monetary incentives scheme. The following two conditions are equivalent.

(1) $\Pi_{M I X}^{*} \geq \Pi_{M O N}^{*}$

(2) $E[q] \geq 0$

Proof of lemma 1.

$$
\begin{aligned}
\Pi_{M O N}^{*} & =\sum_{i=1}^{n} p_{i}^{H}\left(x_{i}-w^{*}\left(x_{i}\right)\right) \\
\Pi_{M I X}^{*} & =\sum_{i=1}^{n} p_{i}^{H}\left[x_{i}-c\left(s^{*}\left(x_{i}\right)\right)-w_{m i x}^{*}\left(x_{i}\right)\right]
\end{aligned}
$$

Thus:

$$
\Pi_{M I X}^{*} \geq \Pi_{M O N}^{*} \Leftrightarrow \sum_{i=1}^{n} p_{i}^{H}\left[w^{*}\left(x_{i}\right)-c\left(s^{*}\left(x_{i}\right)\right)-w_{m i x}^{*}\left(x_{i}\right)\right] \geq 0
$$

That is :

$$
E[q] \geq 0
$$

Proof of theorem 1. The proof consists in showing that $E[q]>0$. Using lemma 1, this amounts to show that:

$$
\Pi_{M I X}^{*}>\Pi_{M O N}^{*}
$$

Let :

$$
C=\left\{\begin{array}{c}
\left(\left\{w\left(x_{i}\right)\right\}_{i=1}^{n},\left\{s\left(x_{i}\right)\right\}_{i=1}^{n}\right): \sum_{i=1}^{n} p_{i}^{H} \tilde{u}\left(w\left(x_{i}\right), s\left(x_{i}\right)\right)-v\left(e^{H}\right)=\underline{U} \\
\text { and } \sum_{i=1}^{n}\left(p_{i}^{H}-p_{i}^{L}\right) \tilde{u}\left(w\left(x_{i}\right), s\left(x_{i}\right)\right)=v\left(e^{H}\right)-v\left(e^{L}\right)
\end{array}\right\}
$$

Clearly, the optimal solution of program (PMIX) is such that $\left\{w^{*}\left(x_{i}\right), s^{*}\left(x_{i}\right)\right\}_{i=1}^{n} \in$ $C$. The set $C$ also writes:

$$
C=\left\{\left(\left\{w\left(x_{i}\right)\right\}_{i=1}^{n},\left\{s\left(x_{i}\right)\right\}_{i=1}^{n}\right): \sum_{i=1}^{n} p_{i}^{L} \tilde{u}\left(w\left(x_{i}\right), s\left(x_{i}\right)\right)=\underline{U}+v\left(e^{L}\right)\right\}
$$

Now let take $\left\{w^{*}\left(x_{i}\right)\right\}_{i=1}^{n}$ the optimal solution of program (PMON). Let determine $\left(\left\{\bar{w}\left(x_{i}\right)\right\}_{i=1}^{n},\left\{\bar{s}\left(x_{i}\right)\right\}_{i=1}^{n}\right) \in C$ such that :

$$
w^{*}\left(x_{i}\right)=\bar{w}\left(x_{i}\right)+\bar{s}\left(x_{i}\right) \quad, i=1 \ldots n
$$

Such a $\left(\left\{\bar{w}\left(x_{i}\right)\right\}_{i=1}^{n},\left\{\bar{s}\left(x_{i}\right)\right\}_{i=1}^{n}\right)$ necessarily exists according to Borsuk's theorem on nonlinear equations system. But, by assumption 3:

$$
\sum_{i=1}^{n} p_{i}^{H} \bar{s}\left(x_{i}\right)>\sum_{i=1}^{n} p_{i}^{H} c\left(\bar{s}\left(x_{i}\right)\right) \quad, \forall i=1 \ldots n
$$

We finally get :

$$
\underbrace{\sum_{i=1}^{n} p_{i}^{H}\left(x_{i}-w^{*}\left(x_{i}\right)\right)}_{\Pi_{M O N}^{*}}<\underbrace{\sum_{i=1}^{n} p_{i}^{H}\left[x_{i}-\bar{w}\left(x_{i}\right)-c\left(\bar{s}\left(x_{i}\right)\right)\right]}_{\Pi_{M I X}}
$$


Let recall that the optimal solution of program (PMIX), $\left\{w^{*}\left(x_{i}\right), s^{*}\left(x_{i}\right)\right\}_{i=1}^{n} \in C$. But by definition we have : $\Pi_{M I X}^{*} \geq \Pi_{M I X}$. Hence :

$$
\Pi_{M I X}^{*}>\Pi_{M O N}^{*}
$$

It remains to show that :

$$
\sum_{i=1}^{n} p_{i}^{H} \tilde{u}\left(w_{m i x}^{*}\left(x_{i}\right), s^{*}\left(x_{i}\right)\right)-v\left(e^{H}\right)=\sum_{i=1}^{n} p_{i}^{H} u\left(w^{*}\left(x_{i}\right)\right)-v\left(e^{H}\right)
$$

This comes directly from the fact that the agent has the same reservation utility under (PMIX) and (PMON).

Proof of Corollary 1. We know that

$$
\Pi_{M I X}^{*}>\Pi_{M O N}^{*}
$$

If we take for example $0<\varepsilon<\Pi_{M I X}^{*}-\Pi_{M O N}^{*}$, and if we build another non-purely monetary incentive scheme with :

$$
\begin{aligned}
w\left(x_{i}\right) & =w_{m i x}^{*}\left(x_{i}\right)+\varepsilon \\
s\left(x_{i}\right) & =s^{*}\left(x_{i}\right), \quad \forall i=1 \ldots n
\end{aligned}
$$

then we get our result.

Proof of proposition ??. This result is the equivalent of theorem 1 when the Principal does not know (and has no prior) the probability distribution of $\theta$ but knows that there exist (at least) two symbols $\omega^{\prime}, \omega^{\prime \prime} \in \Omega$ such that $\omega^{\prime} \succ \omega^{\prime \prime}$. We can therefore use the same technology of proof. 


\section{REFERENCES}

[1] AKERLOF, G. and KRANTON, R. (2005). "Identity and the Economics of Organizations". Journal of Economic Perspectives, Winter 2005, 19, pp. 9-32.

[2] AURIOL, E. and RENAULT, R. (2003). "Status and Incentives". IDEI Working Paper, 41 pages.

[3] BENABOU, R. and TIROLE, J. (2003). "Intrinsic and Extrinsic Motivation". Review of Economics Studies, 70, pp. 489-520.

[4] BAKER, G., JENSEN, M. and MURPHY, K. (1988). "Compensation and Incentives: Practice vs. Theory". Journal of Finance, 43, pp. 593-616.

[5] DALE-OLSEN, H. (2006). "Wages, fringe benefits and worker turnover". Labour Economics, 13(1), pp. 87-105.

[6] DALE-OLSEN, H. (2005). "Using linked employer-employee data to analyze fringe benefits policies. Norvegian experiences". Mimeo Institute for Social Research, 20 pages.

[7] DECI, E. (1975), Intrinsic Motivation, New York: Plenum Press.

[8] DECI, E. and RYAN, R. (1985). Intrinsic Motivation and self-determination in human behavior, New York: Plenum Pres.

[9] ENCINOSA, W., GAYNOR, M. and REBITZER, J. (1997). "The Sociology of Groups and the Economics of Incentives: Theory and Evidence on Compensation Systems". NBER Working Paper, n. 5953.

[10] FEHR, E. and GACHTER, S. (1998). "Reciprocity and Economics: The Economic Implications of Homo Reciprocans". European Economic Review, 42, pp. 845-859.

[11] FREY, B. (1997). "A Constitution for Knaves Crowds Out Civic Virtues". Economic Journal, 107, pp. 1043-1053.

[12] FREY, B. and OBERHOLZER-GEE, F. (1997). "The Cost-Price of Incentives: An Empirical Analysis of Motivation Crowding-Out". American Economic Review, 87 (4), pp. 746-755.

[13] GOLDMAN, D., SOOD, N. and LEIBOWITZ, A. (2005). "The Reallocation of Compensation in Response to Health Insurance Premium Increases". Economic Letters, 88, pp. $147-151$.

[14] HART, O.D. (2001). "Financial contracting". Journal of Economic Literature, 39, pp. 1079-1100.

[15] HASHIMOTO, M. and ZHAO, J. (2000). "The Labor Market Effects of Non-wage Compensations". Labour Economics, 7, pp. 55-78.

[16] HASHIMOTO, M. and ZHAO, J. (2000). "The Labor Market Effects of Non-wage Compensations". Labour Economics, 7, pp. 55-78.

[17] HUCK, S. KUBLER, D. and WEIBULL, J. (2003). "Social Norms and Economic Incentives in Firms". IUI Working Paper, 30 pages.

[18] KAHNEMAN, D., KNETSCH, J. and THALER, R. (1990). "Experimental Tests of the Endowment Effects and the Coase Theorem". Journal of Political Economy, 98, pp. $1325-1348$.

[19] KREPS, D. (1997). "Intrinsic Motivation and Extrinsic Incentives". American Economic Review, 87 (2), pp. 359-364.

[20] LANE, R. (1991). The Market Experience, Cambridge : Cambridge University Press.

[21] LEPPER, M. and GREENE, D. (1978). The Hidden Costs of Rewards: New Perspectives on the Psychology of Human Motivation, Hillsdale, NY : Erlbaum.

[22] RAJAN, R.G. and WULF, J. (2006). "Are perks purely managerial excess?". Journal of Financial Economics, 79 (1), pp. 1-33.

[23] ROYALTY, A.B. (2000). "Tax Preferences for Fringe Benefits and Workers' Eligibility for Employer Health Insurance". Journal of Public Economics, 75, pp. 209-227.

[24] ROSEN, S. (1974). "Hedonic Prices and Implicit Markets: Product Differentiation in Pure Competition". Journal of Political Economy, 82, pp. 34-55.

[25] WOOD, N. (1998). "What Motivates Best?". Sales and Marketing Management, 150 (9), pp. $70-75$. 
[26] YERMACK, D. (2006). "Flights of fancy: corporate jets, CEO perquisites, and inferior shareholder returns". Journal of Financial Economics, forthcoming.

CNRS, Ecole Polytechnique, Lab. D'econométrie and IRES, Cath.U. of Louvain

E-mail address: patricia.crifo@shs.polytechnique.fr

URL: http://ceco.polytechnique.fr/home/crifo/FR

Centre d'Etude de l'Emploi and University of Evry (EPEE)

E-mail address: marc-arthur.diaye@mail.enpc.fr

URL: http://www.univ-evry.fr/PagesHtml/laboratoires/Epee/EPEE.html 